\title{
The architecture and artistic features of high-rise buildings in USSR and the United States of America during the first half of the twentieth century
}

\author{
Svetlana Golovina ${ }^{1}$, and Yurii Oblasov ${ }^{1 *}$ \\ ${ }^{1}$ Saint Petersburg State University of Architecture and Civil Engineering, Vtoraya Krasnoarmeiskaya \\ str. 4, St. Petersburg, 190005, Russia
}

\begin{abstract}
Skyscraper is a significant architectural structure in the world's largest cities. The appearance of a skyscraper in the city's architectural composition enhances its status, introduces dynamics into the shape of the city, modernizes the existing environment. Its architectural structure which can have both expressive triumphal forms and ascetic ones. For a deep understanding of the architecture of high-rise buildings must be considered by several criteria. Various approaches can be found in the competitive development of high-rise buildings in Moscow and the US cities in the middle of the twentieth century In this article we will consider how and on the basis of what the architectural decisions of high-rise buildings were formed.
\end{abstract}

\section{Introduction}

High-rise buildings in the USSR were difficult to realize for a long time. The reasons for this were in the devastating consequences of the October Revolution and World War II. As a result, the first high-rise buildings in Moscow were erected in 1947-1957. For the Soviet Union, this became a symbolic and breakthrough event. The architecture of high-rise buildings in Moscow has become a new state symbol. This architectural style in the late Soviet architectural criticism was called "Stalin's Empire."

High-rise architecture in the US was created from the middle of the XIX century. The main centers of high-rise construction were New York and Chicago. Nevertheless, by the middle of the twentieth century high-rise buildings were being built in other large cities. The construction of skyscrapers was a phenomenon that was practically and economically profitable for the US as a developing capitalist country. Each skyscraper performed special functions and tasks according to the requirements of the customer. This influence on the expressive architectural decisions of the early skyscrapers. They had detailed facades, architectural elements and forms that represented the popular architectural styles of those years: functionalism, eclecticism, modernity and art deco $[1,2]$.

\footnotetext{
*Corresponding author: archrick@yandex.ru
} 
The architecture of high-rise buildings in Moscow did not appear immediately. It was required to study foreign experience to create new architectural solutions. In 1934 a group of Soviet architects led by two leaders (Iofan B.M. and Shuko V.A.) went to New York. As a result of research on US architecture and partial borrowing of fundamental foundations Soviet high-rise designing developed. At that time the architects of Soviet Union were tasked with the state importance - to build the Palace of Soviets. This symbolic building had to be erected in Moscow. However, after the Second World War, a new idea was formulated - to build not one but several high-rise buildings in the center of Moscow. The Palace of Soviets should become the main building in a single ensemble. After long design work, the Palace of Soviets was never realized. But other high-rise buildings formed the planned ensemble already by 1957 [3].

Inspired by foreign architecture Soviet architects studied construction technology, engineering and design techniques. It was important to avoid the mistakes and difficulties faced by their American counterparts. The experience of borrowing gave new opportunities for high-rise construction in the Soviet Union.

In this article seven high-rise buildings in Moscow are taken for consideration. Several buildings built in the USA during the first half of the 20th century were also selected. The article aims to compare the Moscow and American architecture of high-rise buildings.

\section{Methods}

The architecture of high-rise buildings was carefully studied in a professional community. One of the most famous researchers of Soviet architecture was the critic Khan-Magomedov S.O. He gave the name of the architectural style of the post-war years - "the Stalin's Empire style." Various civil constructions of that period were built in this style, but it was most clearly show in the high-rise buildings of Moscow. Creators of "the Stalin's Empire style" were architects - Iofan B.M., Shchuko V.A. In addition to practical activities, these architects also explored Soviet architecture in the process of its development from a scientific point of view. In the period when construction of high-rise buildings of that period began the most skilled Soviet architect was Oltarzhevsky V.K. His experience was based on work in the construction of high-rise buildings in the United States from 1924 to 1935. Later Oltarzhevsky V.K. became the architect of one of the seven high-rise buildings in Moscow. It was he who became one of the first architects who compared the Soviet and American high-rise buildings including from the point of view of construction technologies.

High-rise buildings and their urban value were studied in American architectural criticism in the 1920s-1930s. Some position about this was provided by the builders of skyscrapers: Farris H., Kahn A., Kahn E. It is also worth mentioning the American architect Wright F. Despite the fact that among his projects there were also high-rise buildings Wright F. claimed that the skyscraper serves only the greed of homeowners.

High-rise buildings in Moscow form the shape of the city for more than 60 years. Their place in the architecture of the city has become part of the whole ensemble. Formation of the city center is the main compositional task performed by these objects.

In this article we will consider seven high-rise buildings: the administrative building at the Red Gate, the residential building on Kotelnicheskaya Embankment, the administrative building on Smolenskaya Sennaya Square (the building of the USSR Ministry of Foreign Affairs), the building of the Moscow State University name of Lomonosov on the Vorobyovy Gory (MSU building), residential building on Kudrinskaya Square, the building of the Hotel "Leningradskaya", the building of the Hotel "Ukraine".

From the extensive list of US skyscrapers, we choose the buildings closest in architecture. In general, we will consider buildings built in New York and several in other US cities. For the analysis we choose the following buildings: the Empire State Building, the Chrysler 
Building, the Wall Street 40 (The Trump Building),the Chicago Board of Trade, the Manhattan Municipal Building, the Woolworth Building, the Tudor City, the Palmolive Building.

In this article, we will set the task of analyzing buildings on three criteria: the townplanning role, the architecture of buildings and the artistic features of buildings.

As the first criterion for analysis we consider the urban planning environment - the composite space formed around architectural sites in Moscow and the United States. We analyze the connection between a skyscraper and a city. We consider the natural landscape as the base on which the city was formed and how the perception of the landscape in the process of city development has changed.

As the second criterion we analyze the construction of buildings in Moscow and the United States. As a material for analysis we consider graphical schemes. On these schemes in generalized forms we compare the compositional character of Soviet and American buildings. We analyze the compositional formation of volumes and facades. As an illustration we suggest the aforementioned schemes.

The third criterion is to consider the artistic image of the objects. We identify the features of some historical objects applied in the details and in formation of high-rise buildings. In general terms we consider the symbolism and significance of the proposed examples. The task is to reveal the artistic character of the high-rise buildings of our study. For illustration we use photographic images of historical buildings and architectural details.

The proposed analysis will allow us to consider the high-rise architecture of the USSR and the USA in the middle of the 20th century from different sides. The expected result of the analysis is the identification of pros and cons in the architecture of the objects under study. It is also interesting to consider the origins of the development of high-rise construction as a global phenomenon. For discussion we make a conceptual analysis of the development of high-altitude architecture.

\section{Results}

\subsection{Town-planning role of objects}

In the process of mastering foreign experience, a number of problems arose before Soviet architects. The main problem was that the urban planning of American cities was based on an orthogonal network of streets. In formed quarters the skyscrapers were built. The situation in Moscow was completely different. Urban spaces were formed on the basis of centuriesold conditions. This structure was close to the old cities of Europe. For example, some highrise buildings before the Second World War were erected in Europe as well. Despite this Soviet architects had to combine the ancient town plan and modern high-rise buildings. This task caused many difficulties. But in the process of the general reconstruction of Moscow since 1935, many modern solutions became available [4].

By the beginning of the 1930s in the United States there were more than a hundred highrise skyscrapers. In the USSR it was impossible to create a larger or equal number of highrise buildings. The task was to correctly create even a few buildings that could organize the urban space of Moscow.

The distinctive features of US cities also included a small distance between skyscrapers. This complex situation affected the excessive blackout of the streets. This problem is tried to solve with a reduction in the size of the building with each upper level. From the total mass of the buildings the skyscrapers were tried to allocate by expressive towers: pyramidal, terraced and other more complex top. Well thought detailing of the lower floors that was close to human scale also characteristic for the architecture of skyscrapers. In the architectural decisions of the Moscow high-rise buildings, it was necessary to take into account that many 
elements of the structures will be clearly visible from different points of view. From the building, a special expressiveness of the architecture was required. This aspect was closely related to the reconstructed urban environment of Moscow $[4,5,6]$.

The urban environment of Moscow was dependent to the natural landscape of the very foundation of the city. The structure of the city was close to the principles of low-rise building structure. The grid of the streets was also influenced by the location of the Moscow Kremlin. The shape of the city was repeating the landform in which the dominants of temple towers, bell towers and other high-rise buildings were arising.

It is important to take into account that the architecture of Moscow is not completely preserved today. Several times the city was exposed to destructive fires and other disruptions under the influence of various anthropogenic factors.

The building of the Moscow State University (further MSU) was located on a high plateau on the bank of the Moskva River.

The building of the Hotel "Ukraine", residential building on Kotelnicheskaya Embankment, was built along the water area in some the places of bends and ramifications of the Moscow River.

The building at the Red Gate and the building on Kudrinskaya Square were included in the ensemble of the Garden Ring - the main street enveloping the historical center of Moscow.

Hotel "Leningradskaya" included in the composition of the formed Area of Three Railway stations as main part of the city.

The building of the Ministry of Foreign Affairs of the USSR became dominant, built along the axis of the city that oriented to the Borodino bridge.

As we can see, three of the four buildings were located in key points of the city's natural landscape, and the rest of the buildings were included in the city plan. The renewed urban environment also repeated the historical structure of Moscow and preserved its townplanning traditions.

New high-rise buildings have changed the skyline of Moscow. After the reconstruction, the streets and other urban spaces were significantly expanded. The perspective of the streets became more dynamic and was defined by compositional accents far apart from each other. It is worth noting that the modern construction of skyscrapers in Moscow was conducted delicately. New high-rise dominants were erected in the new district of the city.

The formation of US cities was completely different. The first feature was that the cities were built from scratch and quickly built up on the existing territory. While the US cities were relatively young in a historical context, they had an increased density of buildings and population. The second feature was that the main destruction of urban buildings was caused only by fires and various natural phenomena. They have not experienced a deliberately destructive impact of anthropogenic character and have retained some primary structure. The third feature was the formation of skyscrapers which was determined by the needs of economic growth. In the middle of the twentieth century, the world financial and industrial center developed in the United States. This fact became the reason for mass building of a skyscraper as a special building for a modern type of business. The most optimal was to place the entire company in one building, rather than in a complex of buildings, as it was before $[6,7]$.

The natural environment of New York and Chicago have a fairly flat landscape. The architecture of skyscrapers makes the urban environment similar to mountains and canyons. High-rise buildings in the US cities completely change the landscape and dominate the earlier architecture of average and low-storey buildings. Over time this environment has become a new rapidly spreading worldwide phenomenon of urban planning. 


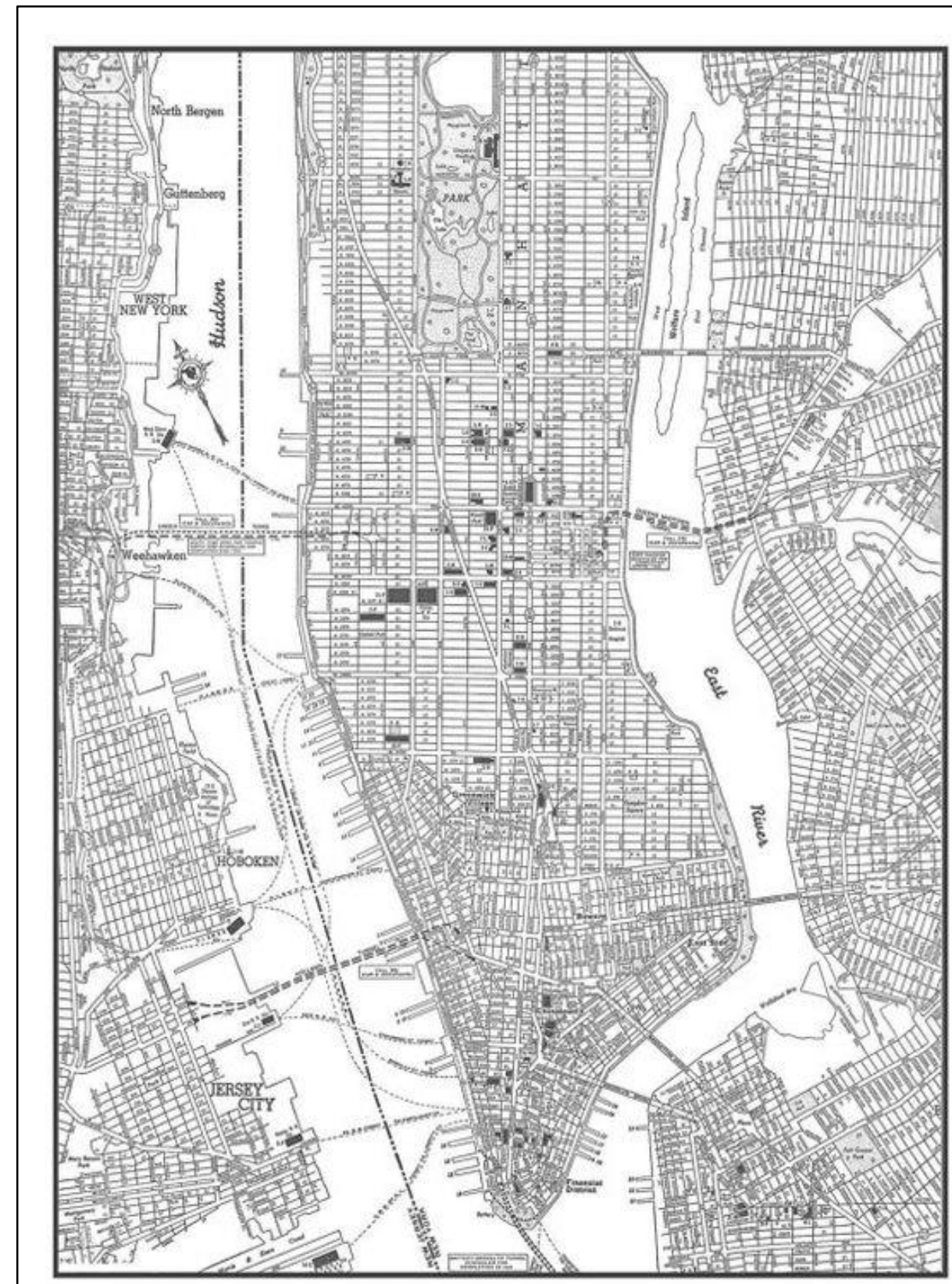

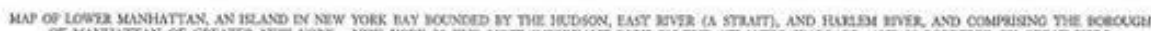

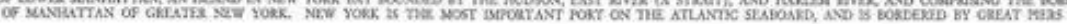

Fig. 1. New York city Manhattan street map. 1944. [21] 


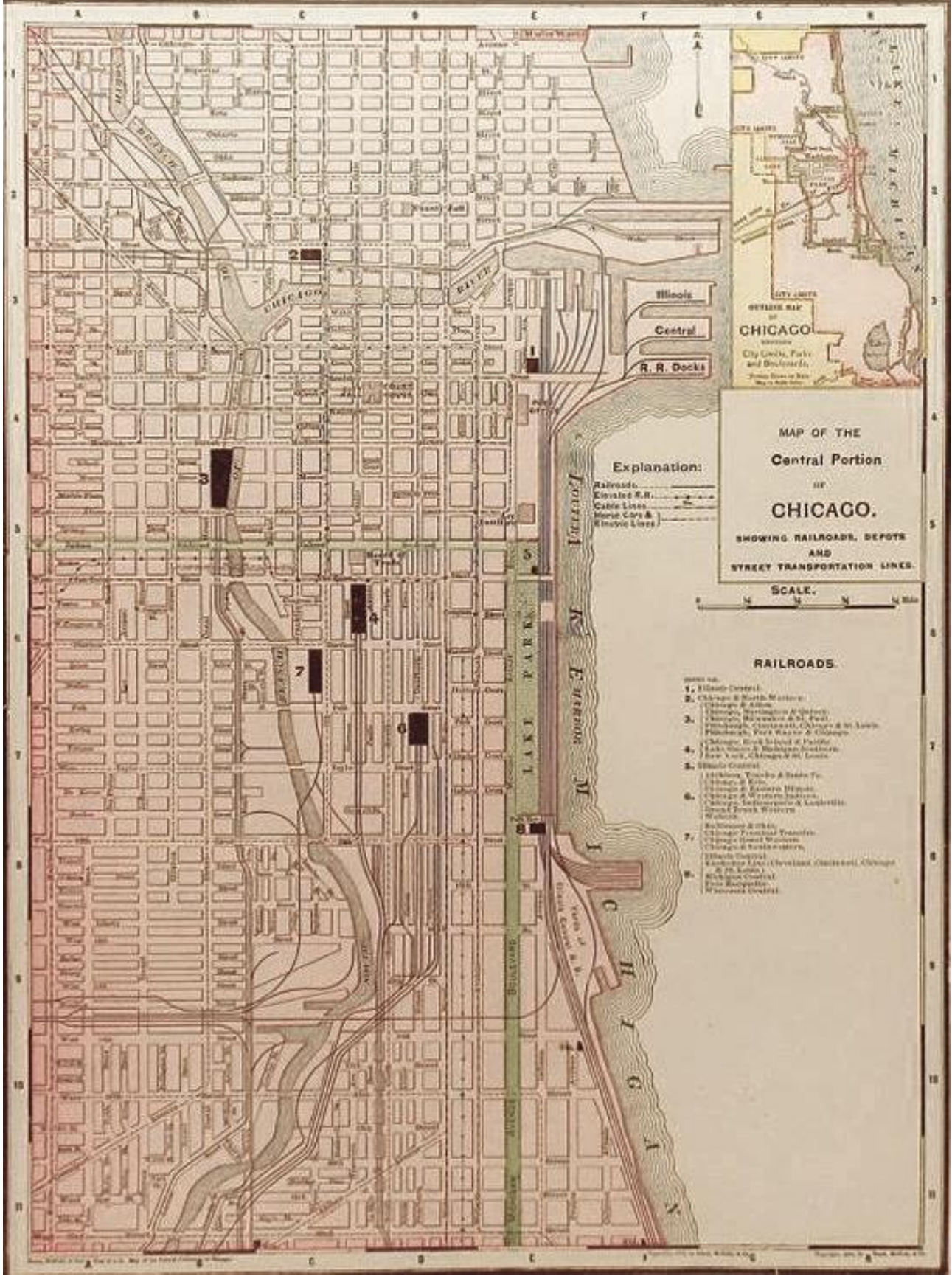

Fig. 2. Chicago city street map. 1901s. [22] 


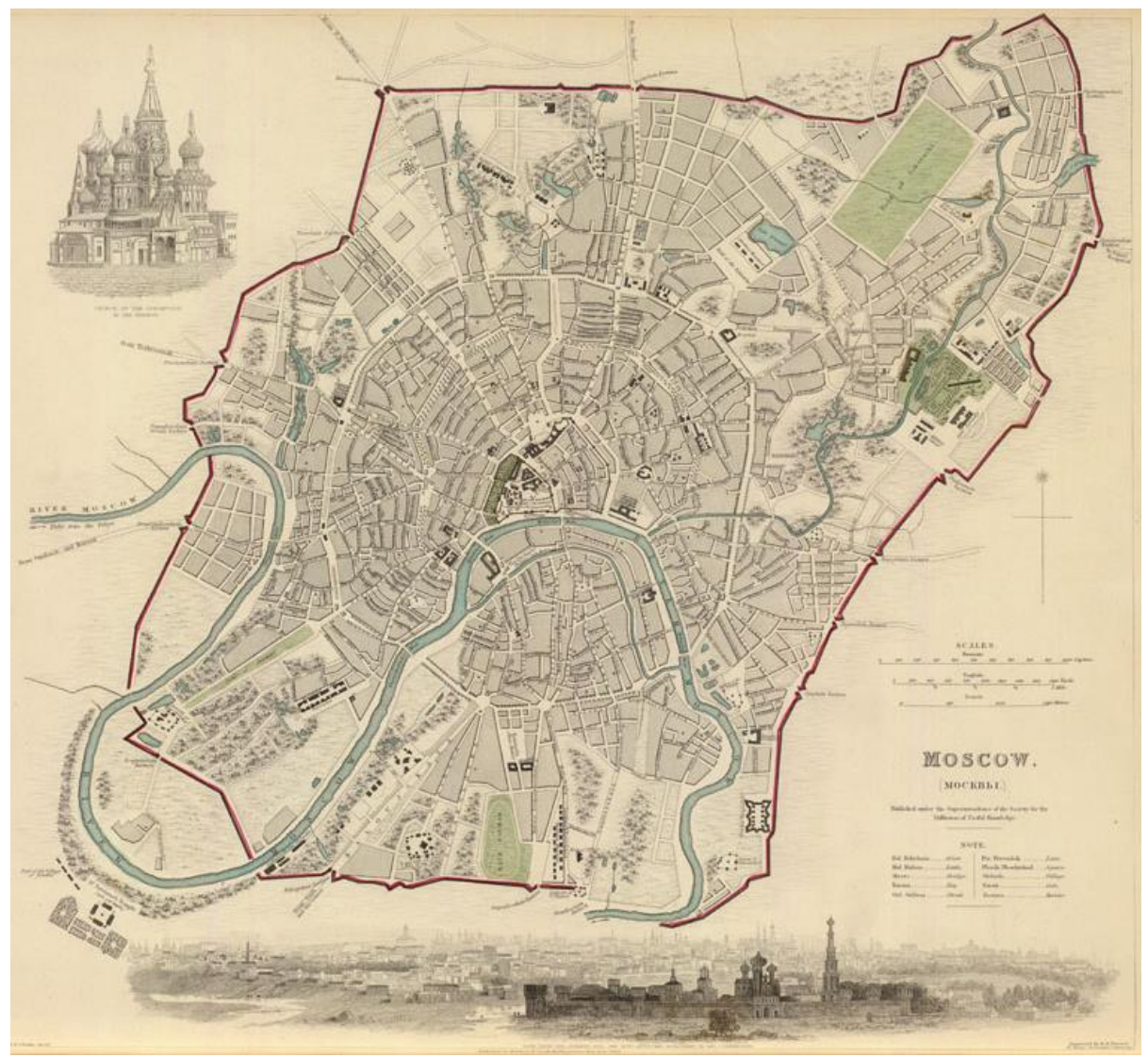

Fig. 3. The city plan of Moscow. 1836. (Maps of the Society for the Diffusion of Useful Knowledge.) [23]

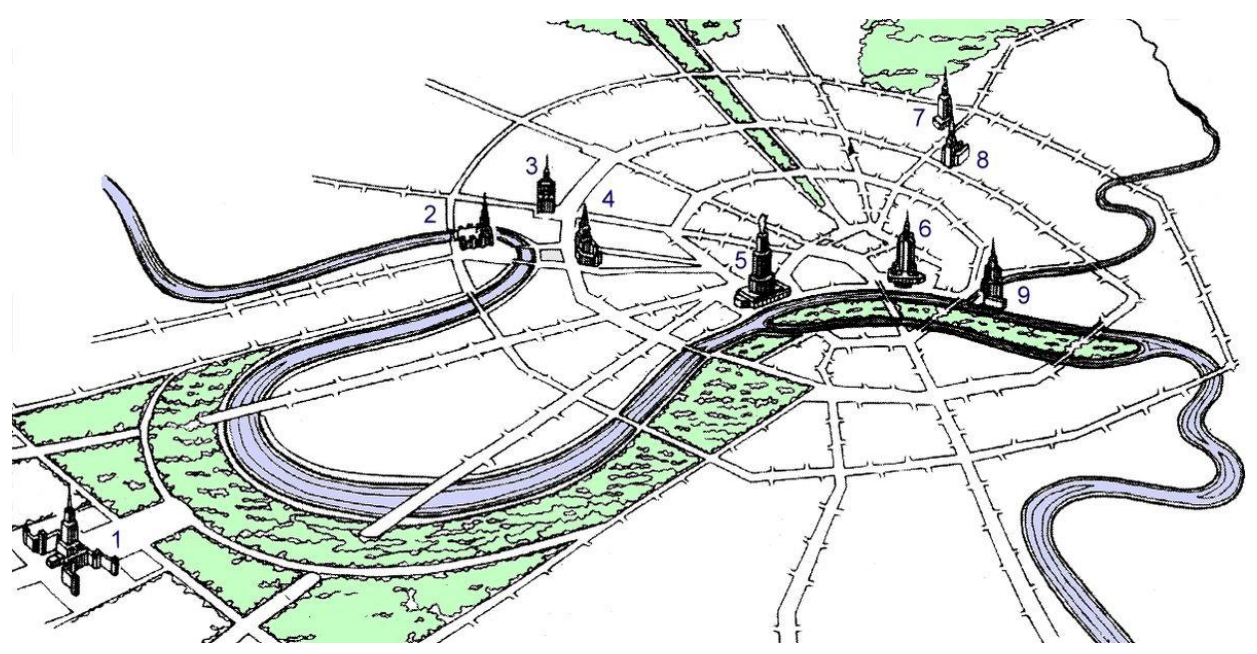

Fig. 4. The projected panorama of high-rise buildings in Moscow. 1 - the building of the Moscow State University name of Lomonosov on the Vorobyovy Gory (MSU building), 2 - the building of the Hotel "Ukraine", 3 - the residential building on Kudrinskaya Square, 4 - the administrative building 
on Smolenskaya Sennaya Square (the building of the USSR Ministry of Foreign Affairs), 5 - the Palace of Soviets (not built), 6 - the administrative building in Zaryadye (not built), 7 - the building of the Hotel "Leningradskaya", 8 - the administrative building at the Red Gate, 9 - the residential building on Kotelnicheskaya Embankment. [24]

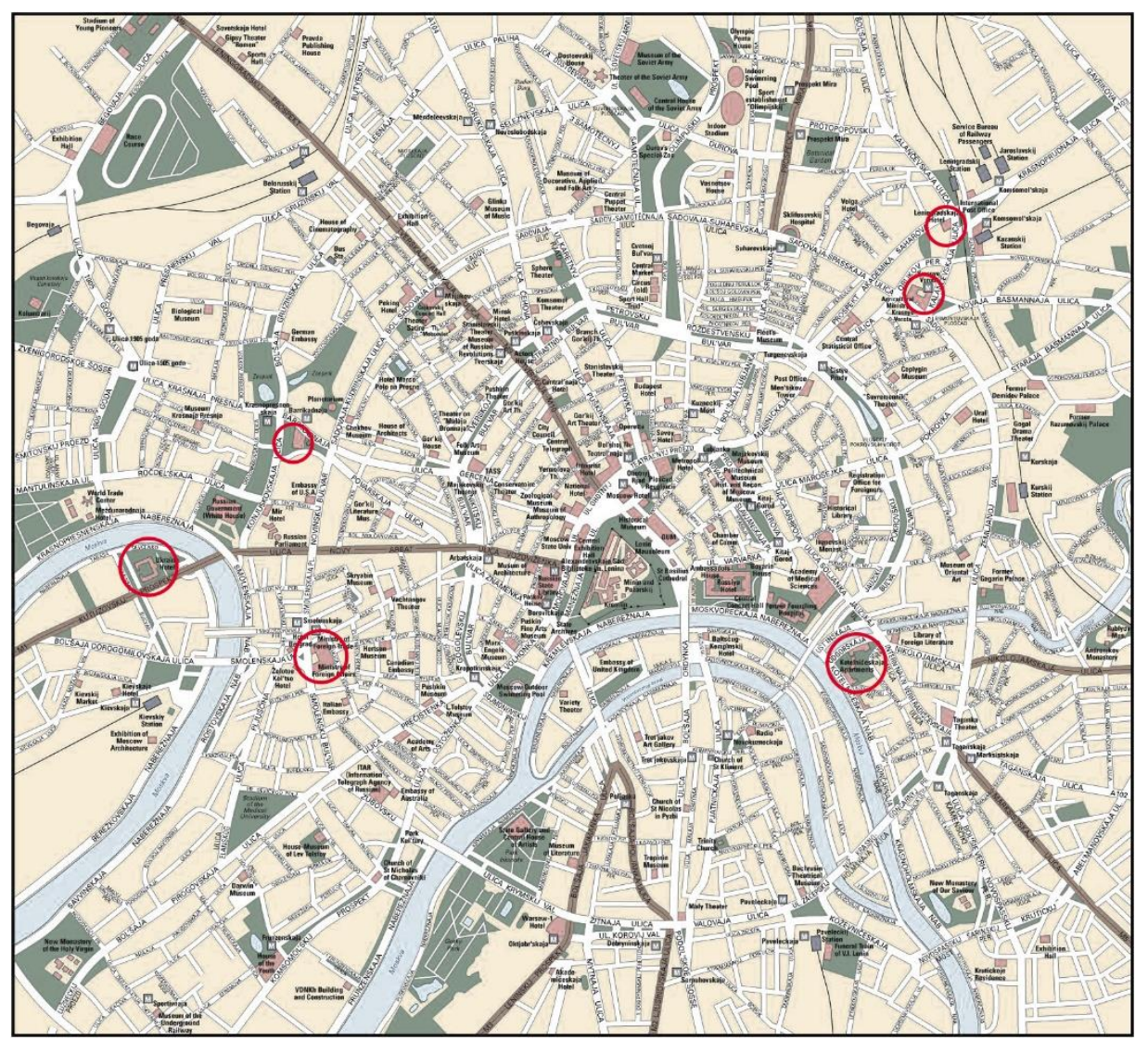

Fig. 5. Street map of downtown Moscow. Present time. High-rise buildings are marked with a red circle. The building of the Moscow State University outside the borders of the map [25]

\subsection{Shape and composition of buildings}

Soviet architects found out when designing high-rise buildings in Moscow that the shape of the building is very important for perceiving the object from different points of view. The experience of architects of the USA offered basically a tower type of a building. The main characteristic of tower-type skyscrapers was the reduction of the floor area with each new level. The level could included more than ten floors. This method was increasing the perspective of the building and reduced the cast shadow.

For the visual facilitation of buildings in Moscow, a multilevel construction principle was also applied. But the ledges of terraces were almost not revealed by the details on the facades in the US architecture. In architecture Moscow high-rise buildings, it was important to show the division into levels. The boundaries of the levels were richly decorated with architectural details. A clear division of volumes and facades was created. Thus an effect was obtained that softens the scale of the high-rise structure. This design of the boundaries of the levels 
has become characteristic of most buildings in Moscow. It should be noted that the first level was often elongated in the plan. At the same time the following levels formed the volume of a building similar to a towers of US skyscrapers $[8,9,10]$.

In article we proposed schemes considered the shape of high-rise buildings in Moscow. Among them we can find the similar image. A characteristic feature is a form that remind the Kremlin towers. In Moscow houses we see a multilevel principle of volumes construction. Towers have the identical shape and similar spires.

Similarity of forms is also present in the skyscrapers of the United States. In the building of Wall Street, 40 (Trump Bulding) the tower is formed from the more massive volume of the building that occupies the quartal. On the diagrams one can see that the multilevel principle of the formation of the skyscrapers towers in American practice has one more feature. In US skyscrapers, the levels are distributed mostly uniformly. In some buildings, the area of floors combined in levels does not differ significantly from the floors of subsequent levels. As an example, could be considered the building of Tudor City and the Manhattan municipal building they have the minimal difference in floor area.

The skyscrapers of the United States buildings had different top of the structures like at the Moscow objects. Often buildings were finished with multi-storeyed volumes which function as ordinary floors of the building. But the Moscow top of the buildings were rich decorated. The big problem was to see architectural details and decorations at the high levels in the close quarters of skyscrapers. The skyscrapers were perceived better on the terraces and roofs of neighboring buildings. This factor greatly influenced the changing architecture of skyscrapers during the twentieth century.

On the diagrams one can see the similarity of Moscow high-rise buildings and American skyscrapers. For example, the building of the hotel "Leningradskaya" and the building of the hotel "Ukraine" are close in shape to the towers of American skyscrapers. The principle of the volume of the building Palmolive Building and the Chicago Chamber of Commerce has in common with the building of the Ministry of Foreign Affairs and the building on Kudrinskaya Square. The shapes of the Empire State Buiding and the Woolworth Building towers that form of a dynamic axis similar to the principle of the MSU building main tower. The heavyweight composition of Tudor Building is close to the building on Kotelnicheskaya embankment.

It can be argued that many principles of building skyscrapers, which were borrowed from American practice, were largely reworked and adapted by Soviet architects. A set of architectural methods developed in the practice of building skyscrapers, found a new unique realize in the USSR.

Table 1. Graphical schemes of Moscow high-rise buildings

The administrative building at the Red Gate

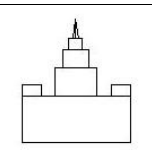

The residential building on
Kotelnicheskaya Embankment

The administrative building on Smolenskaya Sennaya Square (the building of the USSR Ministry of Foreign Affairs)

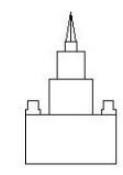


The building of the Moscow State University name of Lomonosov on

the Vorobyovy Gory (MSU building)

The residential building on
Kudrinskaya Square

The building of the Hotel "Leningradskaya"

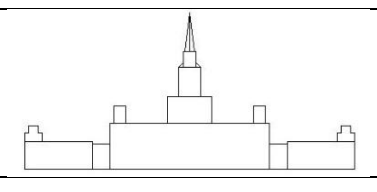

The building of the Hotel "Ukraine"

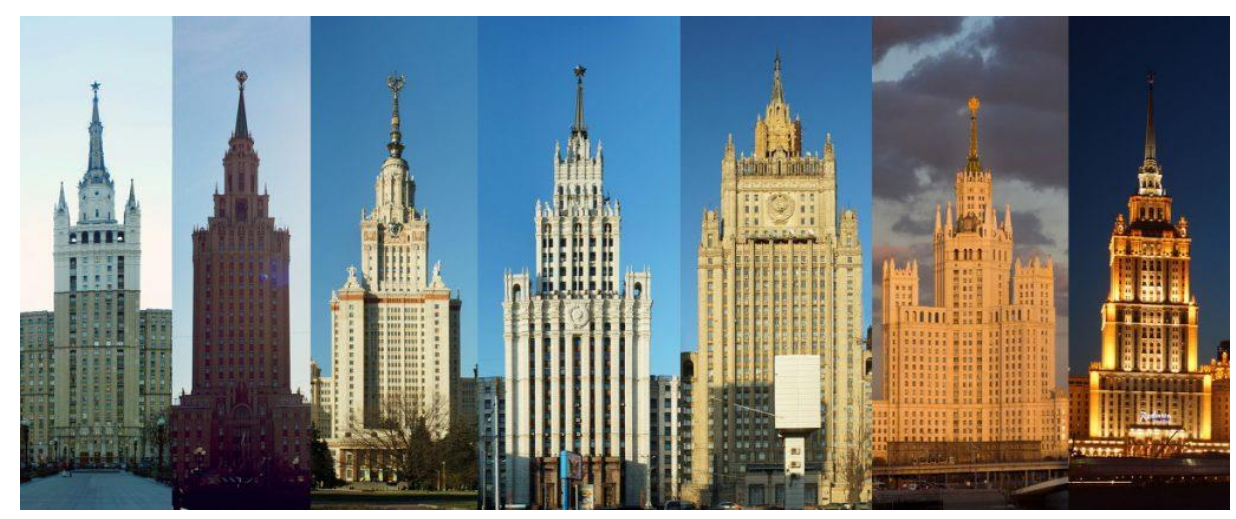

Fig. 5. The pictures of Moscow high-rise buildings

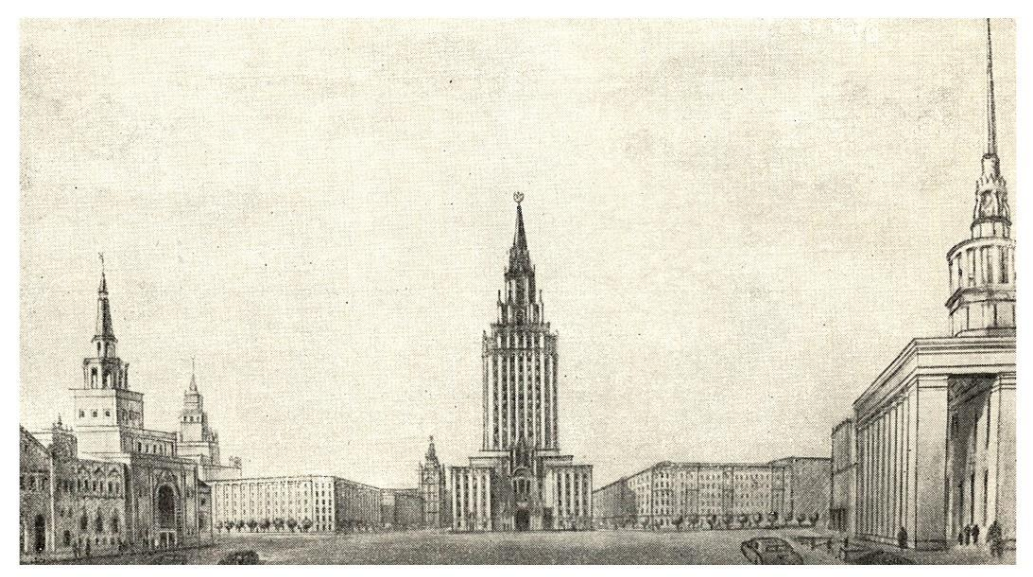

Fig. 6. The project for the construction of the Komsomol square (The square of three stations). [18] 
Table 2. Graphical schemes of US high-rise buildings

the Chrysler Building

the Tudor City

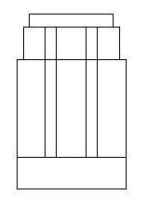

the Woolworth Building

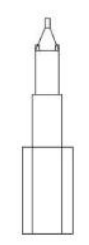

\begin{tabular}{llll}
\hline the Manhattan Municipal Building \\
the Chicago Board of Trade
\end{tabular}




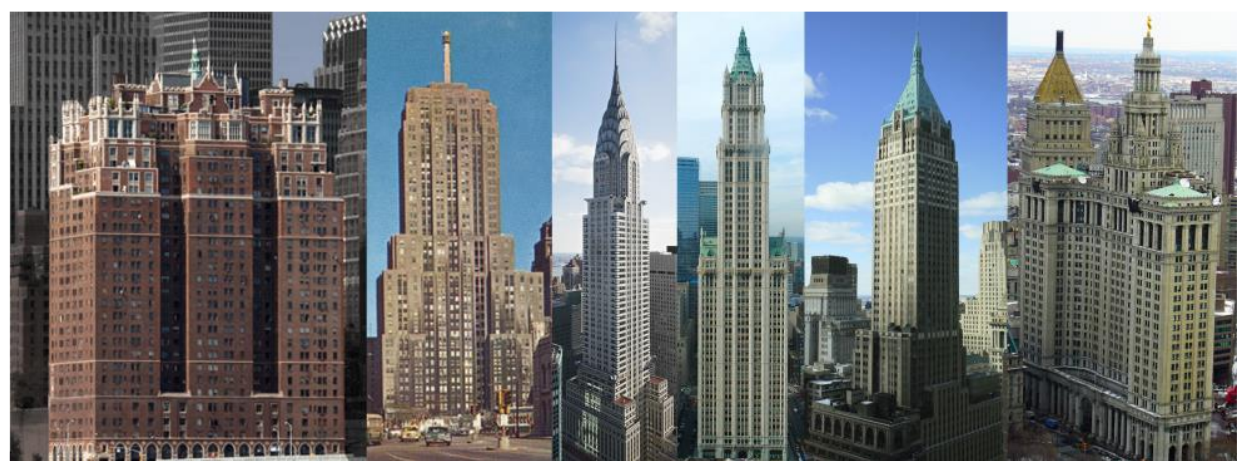

Fig. 8. The pictures of US high-rise buildings

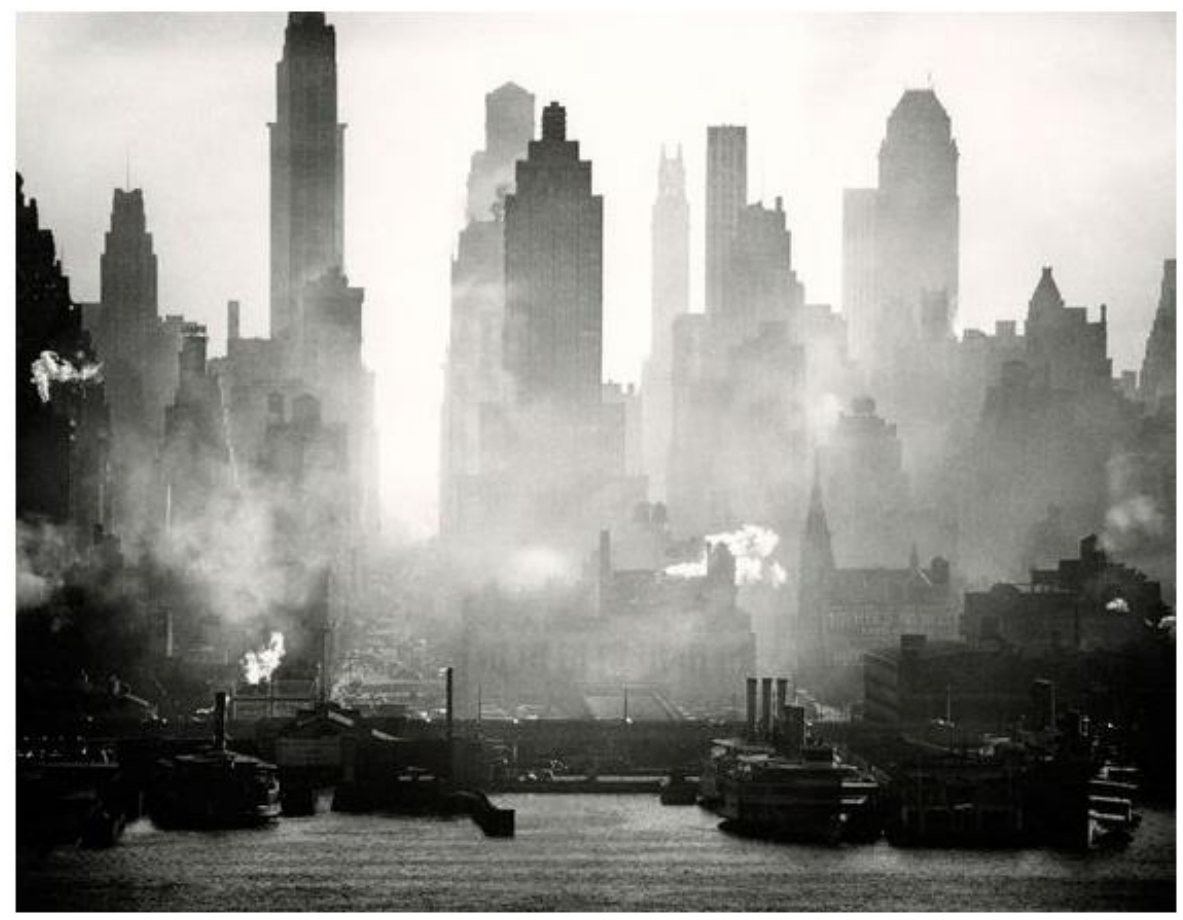

Fig. 7. The New York: 42nd Street View. (Andreas Feininger Archive/Courtesy Zeppelin Museum Friedrichshafen). [26]

\subsection{Imagery}

In this section will considered the artistic features of the architecture of a high-rise building. Consider the artistic analogies of monuments from the history of architecture with high-rise buildings in America and Moscow.

Could be noted the direct parallel of the tower of the American skyscraper, with the shape of the obelisk. Obelisks were erected in memory of outstanding events and had a sacred significance. The top of the buildings in US skyscrapers is close to the obelisk, for example, the building of Wall Street 40 (Trump Bulding) has a four-sided pyramidal finish.

The image of the Gothic churches is also traced in the architecture of the buildings being studied read in the form. The main feature of the Gothic architecture the vertical ribs on the 
facades of the buildings. The same that rows of windows form ribs and niches on facades of skyscrapers. The architecture of the Gothic churches and towers is dynamic. At the same time Gothic architecture fulfilled a strict ideological role for the maintenance of religion and monarchical power in European countries. Many early skyscrapers in the US and Soviet highrise buildings are related to the neo-Gothic eclectic tendencies of the early twentieth century. On the parapets of high-rise buildings in American and Soviet practice, it is easy to find a decor applied according to the principles of Gothic architecture. Among such architectural elements it is worth mentioning, arrows, pinnacles and other details $[11,12,13]$.

The shape of Moscow high-rise buildings is closer to Orthodox church architecture. The principles of the formation of vertical dominants and stable horizontal composition that is typical for this architecture. As an example we can study the Church of the Intercession in Fili, Sukharev Tower and other buildings of early Moscow architecture.

The artistic image of the triumphal arch can be traced in the Moscow buildings. Arch was a majestic object much larger than the scale of human growth. A spectacular gigantic structure was created through which had passing the parades. You can find a similar principle in the architecture of high-rise buildings in Moscow. Especially the first levels of buildings that was stretched horizontally had the large scales. The lower level of the building of the Ministry of Foreign Affairs of the USSR was formed by a large-scale colonnade. There was realized principle of temple propylaeum close to the architecture of ancient Greece. Also in Soviet buildings, details of fortress architecture were used - arrows, swallowtails.

The high-rise buildings studied in this article have architectural details and forms used in the history of architecture. This phenomenon can be explained by the neoclassical and eclectic architectural trend that dominated with avant-garde in the first half of the twentieth century. However, the appeal to traditional forms gave the high-rise buildings a certain appearance. The buildings displayed an artistic image of triumph and success. The buildings with that architecture characters seems quite logical and consistent if we consider it in the complex political context of that period.

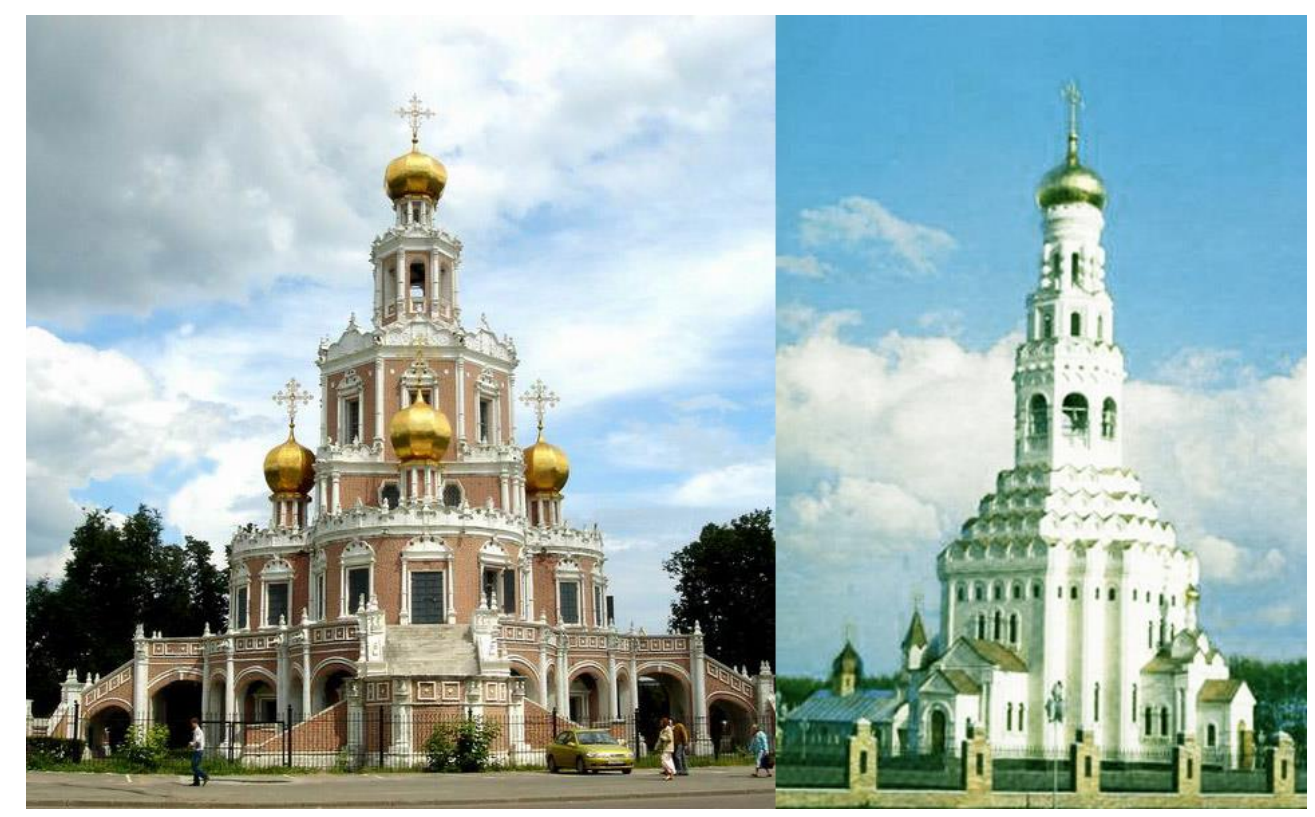

Fig. 8. The orthodox churches architecture. 


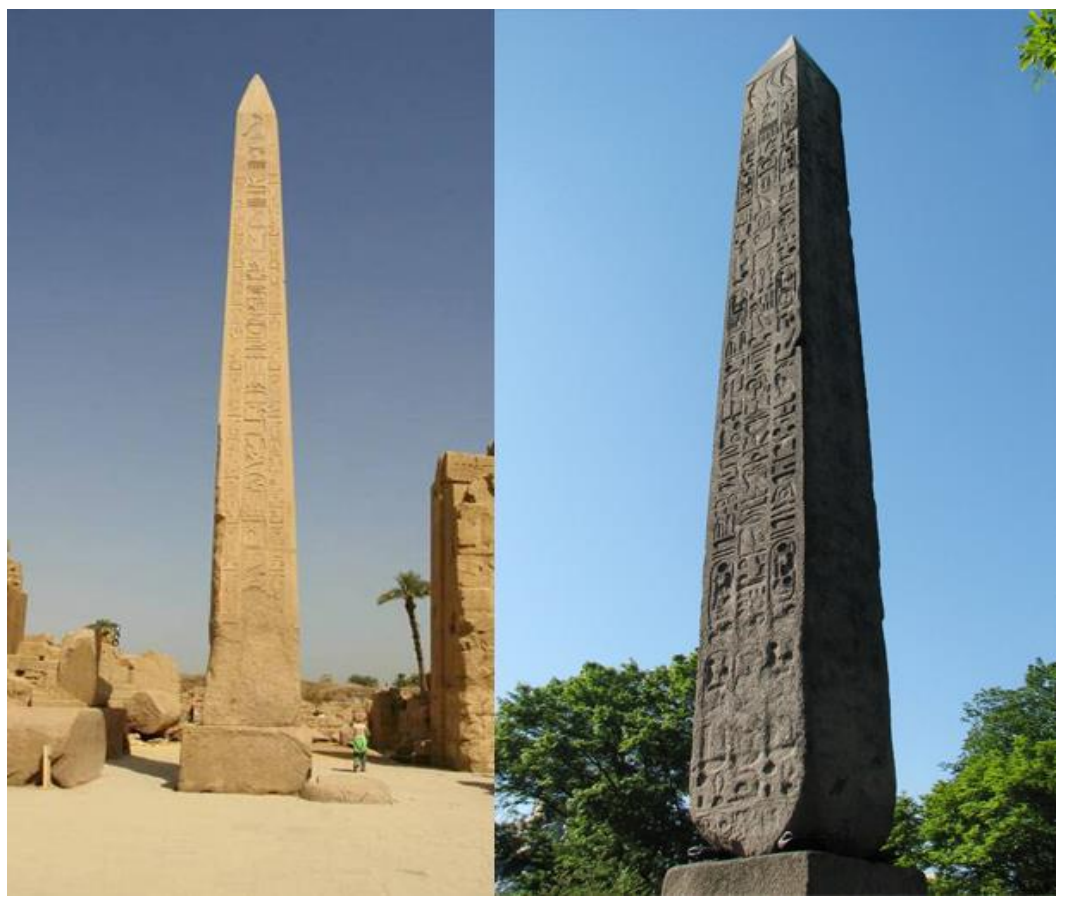

Fig. 9. The Egypt obelisks
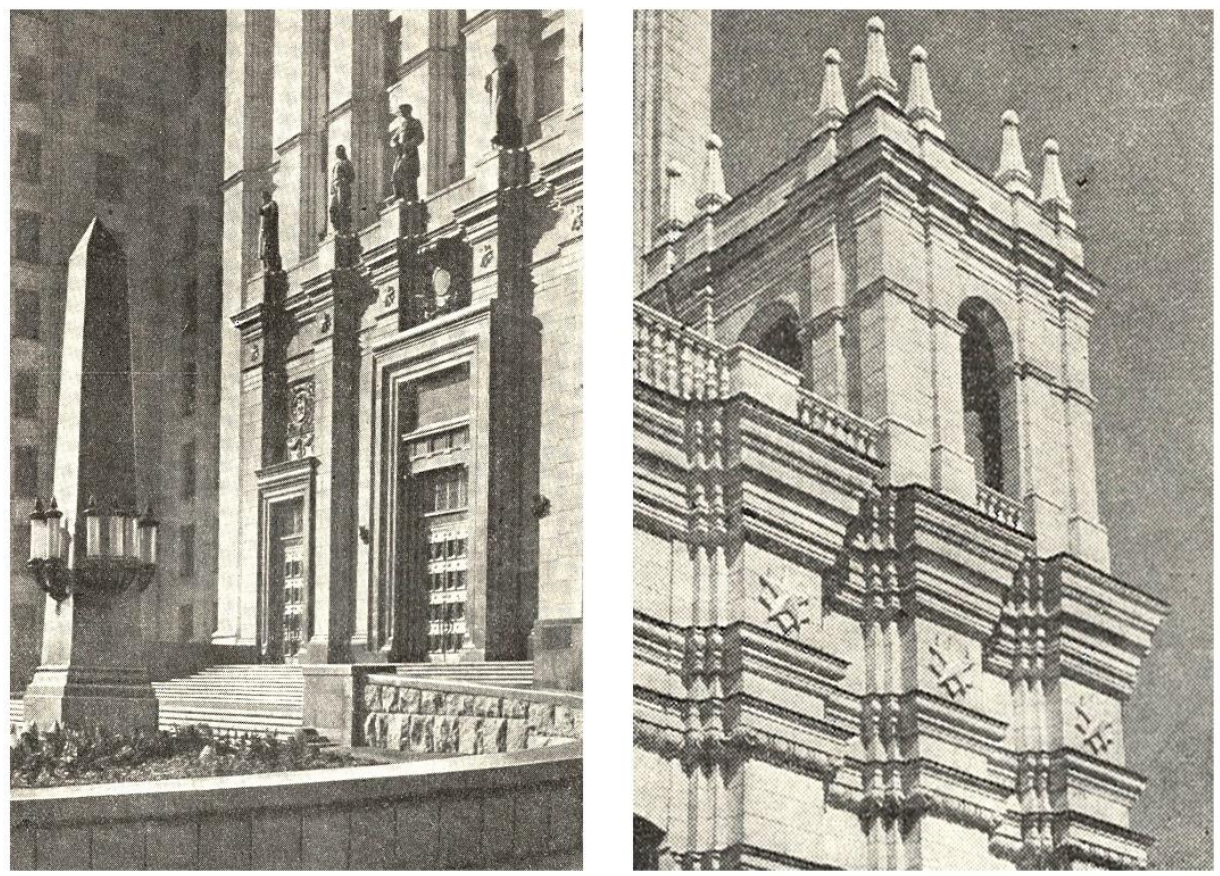

Fig. 10. Forms of obelisks and ancient Russian architecture in high-rise buildings of Moscow. [18] 


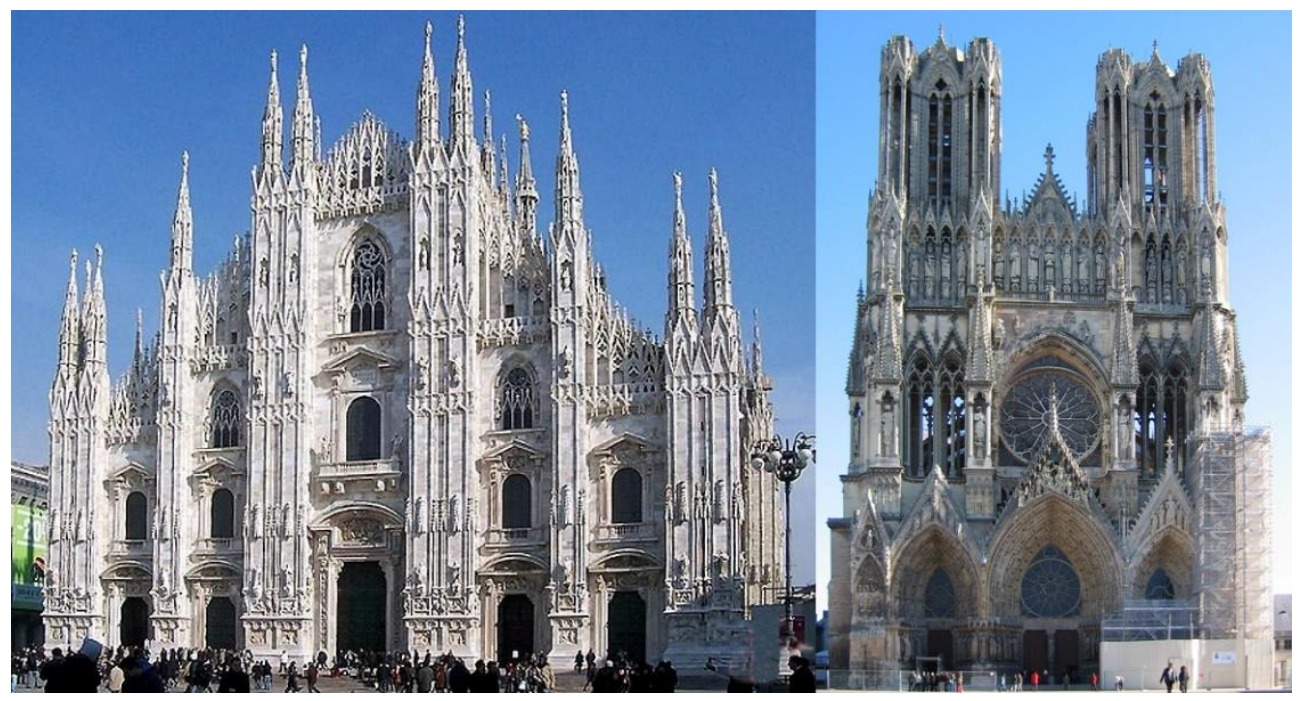

Fig. 11. The gothic churches architecture

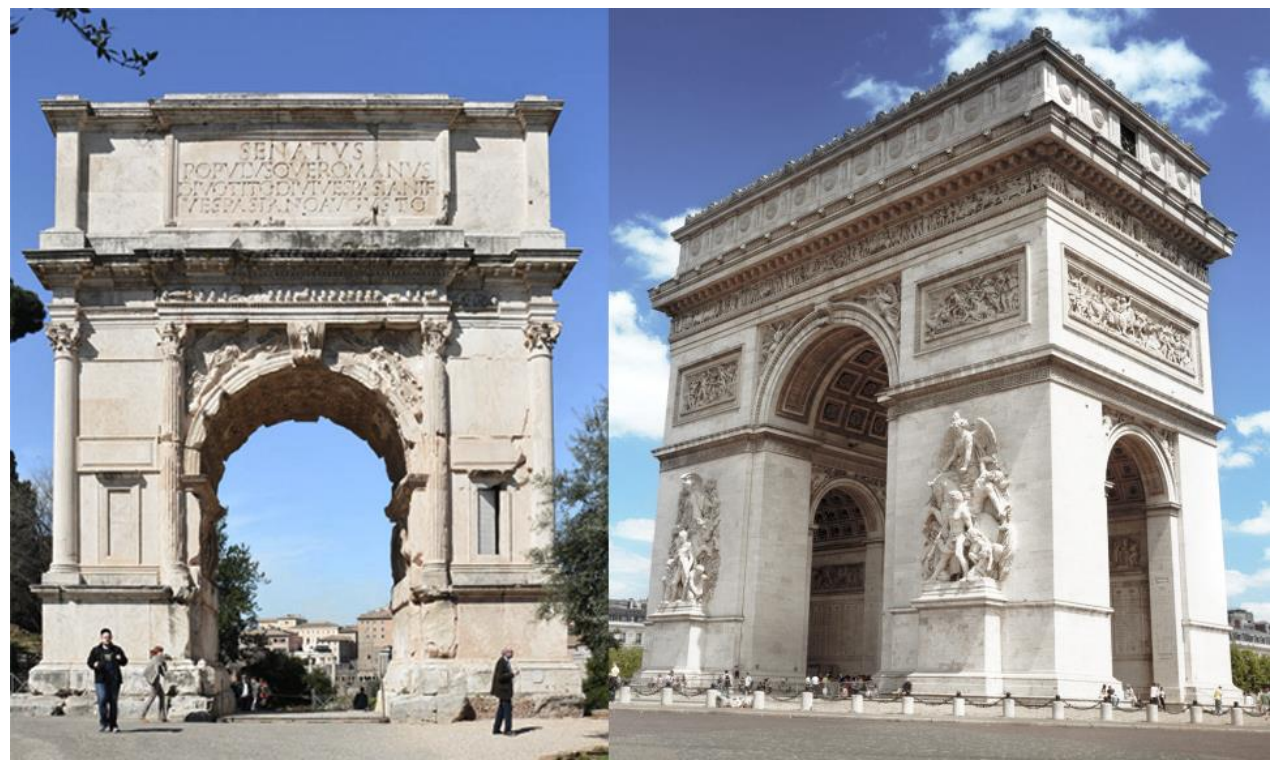

Fig. 12. The examples of triumphal arks 

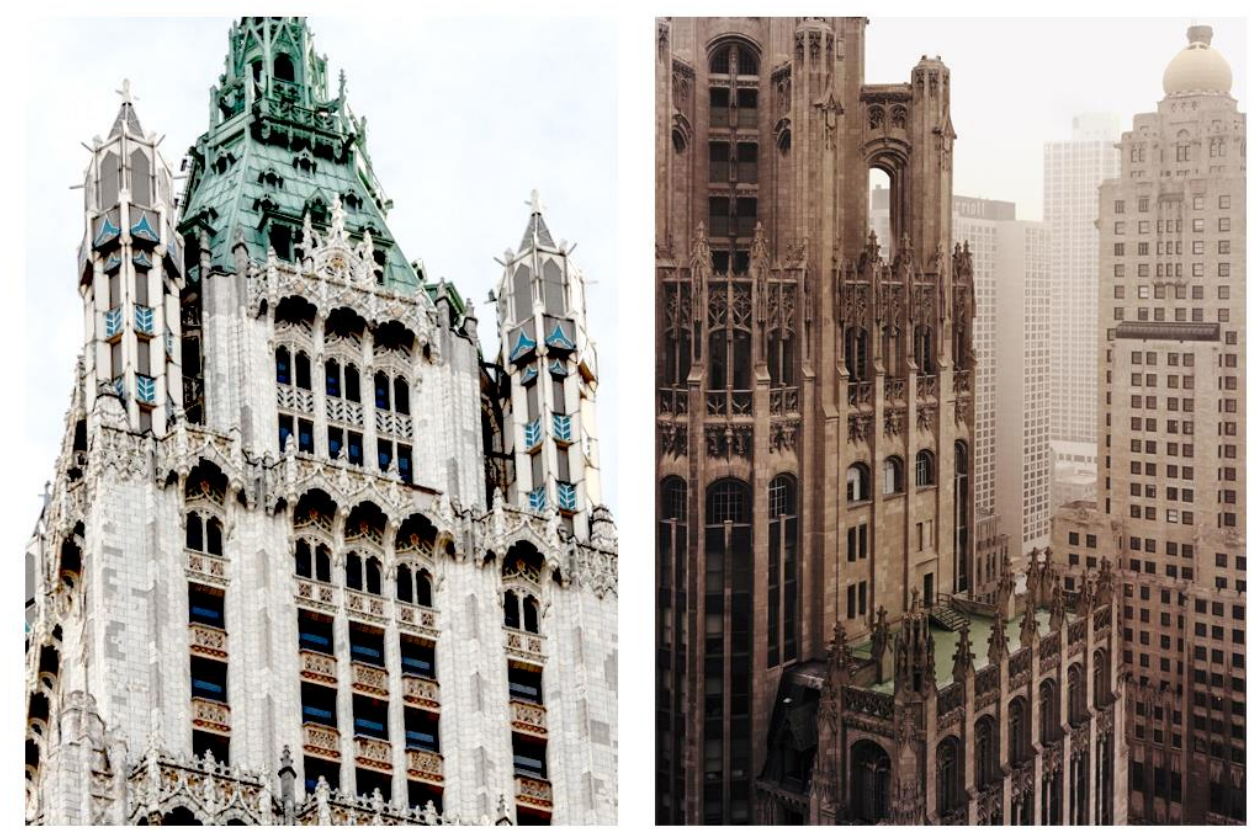

Fig. 13. The forms of Gothic architecture in skyscrapers of New York. [27]

\section{Discussion}

The architecture of American skyscrapers developed during the twentieth century. This process has formed a different form of buildings. All the features of high-rise architecture gradually transformed into a new functional form. As a result, the modern appearance of skyscrapers in the cities of the USA arose under the influence of the early practice of their construction.

The building environment formed by skyscrapers has become an example of urban space contrasted with the established canons of classical architectural composition.

Moscow skyscrapers absorbed the diverse architecture of the city. But their further influence on the development of urban space did not last long. Immediately after the construction of high-rise buildings, the state architectural style changed. It was decided to abandon unnecessary details in the design of buildings. Further high-rise buildings differed from those built in "Stalin's Empire style." We can consider example of a high-rise dominant is the Council House of the RSFSR, built in 1979. This building has an ascetic architecture, but repeats the general compositional techniques of the first high-rise buildings [14].

The investigated structures were formed in opposing economic and political systems being both a visible symbol of success, status, and a rational solution. Moscow high-rise architecture has formed in the USSR the image of the capital renewed after wars and deprivations. Buildings in the center of the city presented a new Soviet state with a new ideology. It showed the capability to significant material achievements [15].

American high-rise constructions marked the newest image of a modern successful city. It became a symbol of top the era of human conflict with nature. Finally, it could be affirmed., that the natural landscape and environment completely subordinated to the genius of human thought. Arrays of skyscrapers and in the modern world are an example of the economic superiority of the city. The image of excellence and triumph in architecture is now formed 
not by a single pillar-like monument, but by a set of dominants that form a single complex of high-rise buildings that prevails over a human scale $[16,17]$.

Despite the active development and globalization of skyscrapers as an architectural unit - it is difficult to consider a skyscraper as a future architecture. In the era of depletion of resources, and heavy burden on the environment - the skyscraper acts as structure that contradicting to these tasks.

It is possible to allocate the global role of each of the considered high-rise architectural concepts according to the results of the research. American architecture marked a new scale of construction, optimized logistics costs for people working in the same system, turning a high-rise building into a commercially viable mechanism. Moscow architecture proposed a different approach. It archaized the imagery of high-rise buildings, to the imagery of medieval and ancient architecture. The skyscraper in Moscow was erected as a monument, as an image of triumph and will. A rational approach was proposed - to save resources, several such monumental buildings and temple-like buildings. It was sufficient to maintain sustainable development and high morale of the society. But widespread high-rise buildings destroy the perception of the building as an outstanding architectural monument $[19,20]$.

Perhaps in our time, when the construction of skyscrapers is conducted in a number of cities in the world, it makes sense to reconsider the role of high-rise buildings. It must be found a way to preserve the existing architectural landscapes. It need to not allowing them to be suppressed by dominant ones and to indicate the boundaries that are acceptable for the urban development of similar structures.

\section{Conclusion}

Based on the results of the article, several factors can be identified that relate and contrast the architecture of Moscow high-rise buildings and American skyscrapers. Our task was to reveal the features of buildings and also to designate the imaginative and philosophical role of highrise constructions. To emphasize the positive aspects of the development of high-rise architecture in Moscow and the United States.

\section{References}

1 P.V. Abrosimov, A.V. Voronkov Construction of a high-rise building Moscow State University (Urban Management, Moscow, 1952)

2 I. Andreev Joseph Stalin's cathedrals (The Echo of the Planet,2013)

3 K. K. Antonov High-rise buildings in Moscow - an outstanding achievement (Soviet architecture and construction equipment, Moscow, 1953)

4 E. Bernasconi How rose high-rise Moscow, Echo of the planet, 2007, 35, 40 - 42.

5 A.A. Vaskin Architecture of "Stalin" skyscrapers. Residential house on Kudrinskaya street (Questions of the humanities, 2007)

6 Yu. P. Volchok Multidimensional spaces of the city. High-rise buildings in Moscow, The Moscow Journal, 2011, Appendix: the history of high-rise construction in Moscow, $2-32$.

7 A.I Kokurin, Accept the proposal of Comrade Stalin, Resolution Council of Ministers of the USSR on the construction of new buildings of the Moscow State University Lenin Hills, 1947 - 1954, Historical archive, 2004.

8 N. N. Kruzhkov High-rise buildings in Moscow: facts from history design and construction, 1947 - 1956. (Samara, 2007)

9 V. Lishak Architecture of Stalin's high-rise buildings (The World of Stamps, 2013) 
10 K. P. Mikhailov, The jump in height. High-rise buildings of Moscow as creations architecture of the fourth dimension, Moscow heritage, 2008, 6, 44 - 51.

11 V.K. Oltarzhevsky Construction of high-rise buildings in Moscow. (Moscow, 1953)

12 B. Rubanenko, Architecture of a high-rise building on Kotelnicheskaya embankment in Moscow, Architecture of the USSR, 1952.

13 I. Semenova The point of architecture is to serve people! (Moscow heritage. - 2014)

14 A. Tarkhanov Moscow skyscrapers, Kommersant, 1997.

15 N. O. Shashkova Stalin's high-rise buildings: the symbol of the epoch and our heritage (Architecture and construction of Russia. -2015)

16 Christ-Janer Christ-Janer A. Eliel Saarinen: Finnish-American Architect and Educator (Chicago: University of Chicago Press, 1984)

17 Stern 1994 - Stern R.A.M. New York 1930: Architecture and Urbanism between the Two World Wars (New York: Rizzoli, 1994)

18 N. Kuleshov, A. Pozdnev. High-rise buildings of Moscow. (Moscow, Moscow worker, 1954).

19 https:archi.ru/russia/72752/ar-deko-i-istorizm-v-arkhitekture-moskovskikhvysotnykh-zdanii

20 http:retrofonoteka.ru/sovarch/history/index.htm

21 https://www.etsy.com/listing/89167799/vintage-map-of-manhattan-new-york-city

22 https://redbudart.com/2012/06/25/antique-maps-of-american-cities/

23 http://www.p-porfir.ru/oldmap/w024o.htm

24 https://moscow.drugiegoroda.ru/attractions/19581-stalinskie-vysotki/

25 http://www.mappery.com/map-of/Moscow-Map

26 http://www.zeit.de/kultur/kunst/2012-06/fs-new-york-2

27 http://www.2photo.ru/en/post/30781 